\title{
O efeito da Linguística de Corpus na formulação de material didático e na promoção de output significativo em aulas de italiano/LE
}

\section{The effect of Corpus Linguistics in the development of didactic materials and in the production of significant output in Italian/FL classes}

Graziele Altino Frangiotti*

\footnotetext{
* Doutora pelo Programa de Língua, Literatura e Cultura Italianas da Universidade de São Paulo. E-mail: grazielefrangiotti@gmail.com
} 
Resumo: Diante do ainda pequeno número de trabalhos sobre os efeitos da Linguística de Corpus no ensino de italiano como língua estrangeira, o presente estudo busca descrever o funcionamento e os resultados de uma investigação empírica conduzida durante um curso voltado para aprendizes brasileiros adultos. Por meio das transcrições dos diálogos gravados durante a execução de tarefas realizadas em duplas/trios, foi possível diagnosticar o papel desempenhado por dados e material didático provenientes de corpora como uma ferramenta capaz de impulsionar processos associados à aprendizagem.

Palavras-chave: Ensino de italiano como língua estrangeira; Linguística de Corpus; Pedagogia colaborativa; Variação Linguística; Competência comunicativa.

Abstract: Given the small number of studies on the effects of Corpus Linguistics on the teaching of Italian as a foreign language, the present study seeks to describe the functioning and results of an empirical investigation conducted during a course designed for adult Brazilian students. Through the transcriptions of dialogues recorded during the execution of tasks performed in pairs/trios, it was possible to diagnose the role played by data and didactic material based on corpora as a tool capable of boosting processes related to learning.

Keywords: Teaching of Italian as a foreign language; Corpus Linguistics; Collaborative pedagogy; Linguistic variation; Communicative competence. 


\section{Introdução}

A Linguística de Corpus nasce em um contexto no qual os estudos gerativos eram preponderantes. Como se sabe, dentro desse paradigma, o principal objetivo é estabelecer os princípios que norteiam a formação de uma gramática inata responsável pela competência linguística nos seres humanos. Para atingir esse fim, do ponto de vista prático, parte-se de uma visão racionalista, segundo a qual a fonte de dados da investigação científica provém do conhecimento de língua de que dispõe o pesquisador.

A partir de dados presentes em sua própria mente, o linguista formula teorias, não sendo necessária, portanto, a coleta de produções de informantes externos. Com esse procedimento, o pesquisador espera superar os obstáculos colocados pela fala, como as hesitações, as sobreposições de turnos, as interrupções, os lapsos de memória, elementos que, não constituindo objeto de análise da Linguística, atrapalhariam a compreensão do fenômeno linguístico.

Essencialmente oposta ao paradigma gerativo, a Linguística de Corpus assume a perspectiva de que a língua constitui um sistema probabilístico de combinatórias, no qual as unidades são definidas pelas associações que mantêm umas com as outras. Nesse sentido, as pesquisas propostas a partir dessa ótica se fundam em metodologia empírica, baseada, antes de tudo, na formação de grandes conjuntos de textos reais, analisados com vistas a permitir a identificação dos padrões que norteiam o uso real da língua. Assim sendo, a disciplina investiga as formas que são possíveis e prováveis em produções não idealizadas pelo pesquisador, mas sim efetivamente encontradas em contextos reais de comunicação.

Também privilegiando unidades de análise complexas, o campo do ensino-aprendizagem de línguas tem colocado no centro de suas preocupações o trabalho com o texto. Assim, a atividade docente tem se orientado cada vez mais no sentido de adotar a exploração dos mecanismos envolvidos na compreensão e na produção textual como estratégia para o desenvolvimento da competência comunicativa.

TradTerm, São Paulo, v.37, n. 1, janeiro/2021, p. 119-147 Número Especial - Linguística de Corpus www.revistas.usp.br/tradterm 
Nesse cenário, os textos se consolidam como um insumo fundamental para a atividade científica e pedagógica, na medida em que constituem um instrumento imprescindível para que se possa observar e compreender a construção do processo de significação e, por conseguinte, a complexidade envolvida na linguagem.

Tendo em vista o interesse comum dessas duas áreas no texto, fica evidente o produtivo diálogo que elas podem estabelecer. É justamente com base nessa convergência que o presente estudo visa apresentar uma experiência, na qual a Linguística de Corpus alicerçou a construção de material didático e a prática de ensino adotada durante um curso de italiano como língua estrangeira oferecido para aprendizes brasileiros.

Como primeiro passo para nossas reflexões, concentrar-nos-emos na apresentação de como a Linguística de Corpus tem se aproximado do ensino de italiano/LE; em seguida, descreveremos as escolhas metodológicas e as etapas em que foi organizada essa experiência, para, por fim, apresentarmos os resultados obtidos.

\section{A Linguística de Corpus no ensino da língua italiana/LE}

A Linguística de Corpus (doravante LC), desde o seu nascimento, por volta de 1964 (se tomamos como base o ano de publicação do primeiro grande corpus, Brown Corpus), favoreceu estudos interdisciplinares, conectando-se a áreas como turismo, jornalismo, tradução, direito, medicina, política, psicologia, entre outras. Na Itália, somada a essa tendência geral, tem havido grande interesse pelos efeitos que a LC pode gerar na promoção da educação linguística (BARBERA 2015; ZAGREBELSKY 2005). Apesar disso, como afirmado por Guidetti, Lenzi e Storchi (2012: 1), são “mais raros, ainda que não ausentes, os relatos diretos de uma utilização efetiva por parte dos docentes"1.

1 Todas as traduções do italiano ou do inglês são de nossa autoria. No original: "più rare, anche se non assenti le testimonianze dirette di un utilizzo effettivo da parte dei docenti".

TradTerm, São Paulo, v.37, n. 1, janeiro/2021, p. 119-147 Número Especial - Linguística de Corpus www.revistas.usp.br/tradterm 
Observando os estudos da LC relacionados ao ensino de italiano/LE, vemos que uma parcela deles tem sido realizada com o objetivo de descrever a interlíngua dos aprendizes, identificando possíveis etapas de desenvolvimento (FILIPIN; MARDESIC 2013; CALABRESE 2010; Corino 2009; Zuloaga 2009; Colombo 2009; Onesti; SQuartini 2009; Allora; Marello 2008). Além disso, há também estudos, ainda que poucos, que descrevem experiências práticas de como introduzir corpora de aprendizes no contexto educacional (MARELLO 2012). E pesquisas, especialmente de cunho teórico, que procuram sugerir como os recursos disponibilizados pela LC podem ser integrados à atividade docente (Corino 2014; GUIDETTI; LenZI; STORCHI 2012; LAVIOSA 1999).

Focada mais diretamente nesse último propósito, Laviosa (1999) sustenta que o ensino deveria partir sempre de descrições baseadas em corpus, já que elas permitiriam a professores e alunos reconhecer os fenômenos que são mais frequentes, logo otimizando o tempo em sala de aula, que seria utilizado para o tratamento daqueles aspectos que são, de fato, recorrentes na língua-alvo.

A autora vê como uma ulterior vantagem do trabalho com corpus a compreensão por parte do aluno de que forma e função caminham lado a lado, o que significa assumir que o estudo da forma só faz sentido se for feito através de textos autênticos, que possibilitem a reflexão e a identificação das funções desempenhadas pelos mecanismos linguísticos naquele dado contexto.

Além dessas indicações, a pesquisadora sugere ainda que, no caso de alunos que já atingiram um nível avançado de competência comunicativa, ao introduzir o trabalho com corpus, poderia ser adotada uma abordagem indutiva. Nessa perspectiva, os próprios aprendizes seriam responsáveis pela investigação direta do corpus e pelo levantamento das regras de uso. Em alternativa a essa estratégia, que pode eventualmente oferecer inúmeros desafios aos docentes e discentes, poderia também ser adotada uma abordagem mista, na qual o professor recolheria uma amostra dos dados do corpus e a apresentaria aos alunos, para que eles a analisassem indutivamente, manipulando-a posteriormente em exercícios guiados que se prestem a fixar determinadas estruturas.

TradTerm, São Paulo, v.37, n. 1, janeiro/2021, p. 119-147 Número Especial - Linguística de Corpus www.revistas.usp.br/tradterm 
Também favoráveis ao trabalho com corpus como aliado do ensinoaprendizagem de línguas, Guidetti, Lenzi e Storchi (2012) colocam-no como um instrumento "laboratorial”, ou seja, uma ferramenta adequada para que os aprendizes construam "experimentos linguísticos", por meio dos quais se familiarizariam com a elaboração de perguntas de pesquisa, a formulação de hipóteses, o teste de metodologias e, enfim, a depreensão de respostas às questões postas.

Esses autores se alinham a Johns (1997), que se refere aos aprendizes como detetives, compartilhando a visão de que os aprendizes devem ser convidados a "investigar" a linguagem, tornando-se, assim, sujeitos sempre mais ativos, autônomos e protagonistas no processo de aprendizagem.

Para além da investigação da linguagem propriamente dita, que, em si mesma, representaria um momento de descoberta para os estudantes, supomos que o trabalho com corpus poderia trazer efeitos positivos ao fomentar atividades de discussão que os motivariam a "colocar à prova as próprias capacidades de observação e interpretação” (GUIDETTI; LENZI; STORCHI 2012: 7) $)^{2}$.

E aqui residiria, a nosso ver, uma implicação importante: a possibilidade de extrapolar os convencionais e, muitas vezes, artificiais roleplays, criando uma atmosfera de comunicação real durante a aula, na qual estariam todos, efetivamente, envolvidos ao redor de um fim comum: a identificação de padrões de uso.

Do ponto de vista teórico, levar a análise linguística com base em corpus à sala de aula significa combinar, pelo menos, dois conceitos amplamente empregados atualmente na área da Linguística Aplicada: o de problem solving e o de output significativo, bases fundamentais para a aprendizagem colaborativa (FIGUEIREDO 2006; FREITAS; FREITAS 2003; SWAIN 1985, 1995, 2000, 2005; DilLEMBOURG ET AL. 1996; DiLLEMBOURG 1999).

O primeiro desses conceitos, o de problem solving, vincula-se, sobretudo, à esfera dos estudos em Psicologia, mas é comumente transposto

2 No original: “mettere alla prova le proprie capacità di osservazione e interpretazione”.

TradTerm, São Paulo, v.37, n. 1, janeiro/2021, p. 119-147 Número Especial - Linguística de Corpus www.revistas.usp.br/tradterm 
às pesquisas linguísticas. Para sua completa compreensão, é necessário, antes de tudo, que se defina a ideia de problema. Já aqui, no entanto, as pesquisas não são concordes. Cientes dessas divergências, adotaremos a definição de Dunbar (1998), por ser ela mais coerente com a posição aqui assumida.

Segundo o pesquisador, problemas existem "quando um objetivo deve ser alcançado e a solução não é imediatamente óbvia" (DUNBAR 1998: 289)³. Os problemas seriam compostos por quatro componentes centrais: em primeiro lugar, envolveriam um estado inicial (initial state), no qual o indivíduo entraria em contato com o problema. Envolveria, além disso, o estado objetivo (the goal state), ou seja, o estado em que a meta buscada pelo indivíduo é atingida. O terceiro componente se referiria às ações ou operações que o indivíduo precisaria colocar em funcionamento para chegar ao estado objetivo, enquanto o quarto componente seria o ambiente de tarefas em que o indivíduo estaria trabalhando, consistindo nos recursos do ambiente físico que podem, direta ou indiretamente, restringir ou sugerir diferentes maneiras de resolver um problema.

Em sala de aula, entendemos que promover uma didática voltada para o problem solving implique criar situações em que os aprendizes estejam diante de questionamentos cuja solução não é óbvia, não podendo ser encontrada imediatamente. Sendo assim, esse tipo de tarefa deverá requisitar ações ou operações intermediárias, sem as quais o aprendiz não conseguirá cumprir o propósito da atividade, não atingindo, portanto, o chamado "estado objetivo".

Com relação ao segundo conceito, o de output significativo, Swain (1985, 1995, 2000, 2005) o define como uma etapa fundamental na aprendizagem de uma língua estrangeira, já que diz respeito à ocasião em que os aprendizes, focados em seus objetivos comunicativos, são levados a testar aquilo que já sabem e a criar hipóteses sobre aquilo que ainda não sabem.

Nessa ótica, a produção do aluno deixa de ser tratada como um produto final, resultante da aplicação de regras gramaticais à fala, e passa a constituir

3 No original: "when a goal must be achieved and the solution is not immediately obvious".

TradTerm, São Paulo, v.37, n. 1, janeiro/2021, p. 119-147 Número Especial - Linguística de Corpus www.revistas.usp.br/tradterm 
um processo em que, com a intenção de se fazer entender pelos demais, o aluno se engaja, sentindo uma necessidade real de refletir sobre as formas que deverá usar para construir os significados que deseja comunicar.

Durante a produção significativa, o esforço cognitivo envolvido na comunicação estimularia o surgimento de outros processos psicológicos, entre os quais estariam o noticing, o noticing the hole $e^{4}$ o teste de hipóteses.

O noticing é um conceito desenvolvido inicialmente por Schmidt e Frota (1986) e, posteriormente, retomado por Schmidt (1990, 1993, 1994), sendo definido como a etapa na qual o aprendiz nota conscientemente algo novo na língua-alvo. A partir dele, o aluno procuraria compreender o aspecto notado e a integrá-lo progressivamente à sua produção.

Já o noticing the hole, proposto por Swain (1995), refere-se à capacidade de o aprendiz perceber que não consegue formular aquilo que gostaria, seja porque não conhece determinado elemento lexical, seja porque não se lembra ou não sabe como certa estrutura é construída.

As interações entre aprendizes ou entre o aprendiz e um falante mais competente teria também a função de abrir espaço para o teste de hipótese, que seria, "na perspectiva do aprendiz, uma importante 'trilha' refletindo as hipóteses de como dizer (ou escrever) sua intenção” (SWAIN 2005: 476) ${ }^{5}$.

Além de todos esses fatores, ainda segundo Swain, a produção significativa se conectaria profundamente ao diálogo colaborativo (a expressão "diálogo colaborativo" foi posteriormente substituída pela autora pelo conceito de languaging), o qual ocorreria quando a comunicação entre os alunos assume a função de mediar a construção do conhecimento:

quando a língua é usada para mediar a resolução de problemas, se o problema é sobre qual palavra usar ou como melhor estruturar uma sentença que signifique o que você quer que ela signifique ou como explicar os resultados de um experimento, ou como explicar o sentido de uma ação de outra pessoa, ou... então languaging acontece. [...] Isto é, ao falar (ou ao

4 Por se tratar de expressões recorrentes em estudos na área da Linguística Aplicada, não serão propostas traduções aos conceitos de noticing e noticing the hole.

5 No original: "from the learner's perspective, a 'trial run' reflecting their hypothesis of how to say (or write) their intent".

TradTerm, São Paulo, v.37, n. 1, janeiro/2021, p. 119-147

Número Especial - Linguística de Corpus

www.revistas.usp.br/tradterm 
escrever), nós podemos atingir um entendimento novo ou mais profundo (SWAIN 2006: 96-7) ${ }^{6}$.

Levando em consideração todos os aspectos abordados até aqui, partimos da hipótese de que atividades baseadas em corpus podem ser formuladas de modo que o professor, alicerçado por uma análise prévia dos dados, lance perguntas aos alunos, favorecendo o problem solving.

Durante a execução das tarefas, podem-se prever momentos em que a interação entre os alunos seja necessária. O docente poderá solicitar, por exemplo, que os aprendizes troquem impressões sobre os dados, que façam um debate em caso de possíveis conflitos de interpretação ou que negociem para chegarem a um consenso sobre a plausibilidade das inferências. Todas essas etapas fomentarão o diálogo entre os alunos, o que eventualmente poderá promover mais oportunidades de produção colaborativa e reflexão metalinguística contextualizada.

\section{A experiência em sala de aula}

A experiência aqui descrita foi realizada como parte de nossa pesquisa de doutorado (FRANGIOTTI 2019), na qual investigávamos os efeitos da instrução no desenvolvimento da competência sociolinguística em língua italiana, competência essa ligada à capacidade de o aprendiz produzir e reconhecer elementos linguísticos apropriados ao contexto interacional em que atua.

Como parte desse estudo maior, coletamos, na cidade de Roma, textos autênticos pertencentes a quatro gêneros textuais: e-mail, entrevista, mensagem trocada por aplicativo de celular e plantão docente.

Cada um desses gêneros foi selecionado por envolver diferentes canais: o e-mail por ser escrito; a entrevista e o plantão docente, por serem orais; e a

6 No original: "when language is used to mediate problem solutions, whether the problem is about which word to use, or how best to structure a sentence so it means what you want it to mean, or how to explain the results of an experiment, or how to make sense of the action of another, or... that languaging occurs. [...]That is, while speaking (or writing), we may reach a new or deeper understanding".

TradTerm, São Paulo, v.37, n. 1, janeiro/2021, p. 119-147 Número Especial - Linguística de Corpus www.revistas.usp.br/tradterm 
mensagem enviada por aplicativo, por se materializar como texto escrito, mas abranger mecanismos da oralidade.

Além disso, esses gêneros são diferentemente dispostos ao longo do contínuo da formalidade. Os conjuntos de textos compostos por e-mails e entrevistas haviam sido produzidos por alunos universitários com média de idade de 24 anos e tinham como interlocutores professores universitários, 0 que os caracterizavam como mais ligados ao polo da formalidade; já as entrevistas haviam sido feitas entre alunos universitários (mesma média de idade anterior) e a pesquisadora (com 30 anos à época), porém tratavam de assuntos informais em uma atmosfera mais descontraída, contexto que thes conferiu maior informalidade; finalmente, as mensagens de texto haviam sido escritas pelos mesmos estudantes que participaram das entrevistas, os quais as haviam enviado a amigos íntimos, colocando esses textos como amostras de um registro ainda mais informal, se comparados às entrevistas.

De modo mais específico, diante da gama de instrumentos de análise colocada à disposição pela LC, que inclui, entre outras coisas, uma série de programas computacionais voltados ao levantamento quantitativo de dados linguísticos, optamos pela utilização do software AntConc e, em especial, pelo emprego da função Concordance (concordanciador).

Como etapa de preparação dos dados, em um primeiro momento, procedemos à etiquetagem dos textos reunidos, anotando manualmente no corpus os fenômenos linguísticos que seriam posteriormente estudados. Com exceção do corpus de plantões docentes, que possuía nove mil tokens, os demais corpora tinham cerca de dezoito mil tokens cada um.

Um exemplo das etiquetas usadas nas anotações pode ser visto no quadro a seguir:

Quadro 1: Anotações nos corpora

\begin{tabular}{|ll|}
\hline$<\mathrm{f}>$ & expressão de posterioridade \\
$<\mathrm{co}>$ & conjunção \\
$<\mathrm{dd}>$ & deslocamento à direita \\
$<\mathrm{ds}>$ & deslocamento à esquerda \\
$<\mathrm{d}>$ & diminutivo \\
$<\mathrm{su}>$ & superlativo absoluto \\
$<$ pre $>$ & pronome relativo \\
\hline
\end{tabular}

TradTerm, São Paulo, v.37, n. 1, janeiro/2021, p. 119-147 Número Especial - Linguística de Corpus www.revistas.usp.br/tradterm 
A seguir, exemplificamos com um breve excerto o resultado de uma dessas etiquetagens:

io sto pensando di fare l'analisi dei dati come terzo capitolo $<$ cosperché<co $>$ il secondo è veramente enorme e poi $\langle f\rangle$ scrivo $</ f\rangle$ le conclusioni ah no! ora le $\langle f>$ scrivo $</ f>$

No segmento, retirado de um diálogo entre uma estudante e uma professora universitária, percebe-se que a etiquetagem coloca em evidência uma ocorrência de conjunção, nesse caso, causal perché , e duas ocorrências de expressão de posterioridade em scrivo, ambas construídas com a utilização do verbo conjugado no presente do indicativo.

Em seguida à etiquetagem manual dos corpora, fizemos o levantamento de todas as ocorrências dos fenômenos focalizados no estudo por meio da função Concordance e identificamos as variantes a partir das quais as variáveis se realizavam. A partir disso, calculamos as frequências de ocorrência de cada variante e verificamos se os valores variavam consideravelmente de um gênero para outro. Então, com base em bibliografia pertinente e no reconhecimento dos fatores contextuais envolvidos nas interações, passamos ao exame dos possíveis fatores que poderiam estar motivando as divergências quantitativas

Em decorrência desses procedimentos metodológicos e das análises qualitativas implementadas, constatamos a variação de seis fenômenos linguísticos. Foram eles: 1) a forma de expressão da posterioridade verbal; 2) a escolha das conjunções adversativas, causais, concessivas e conclusivas; 3 ) a utilização de unidades lexicais alteradas no diminutivo; 4) o emprego de superlativos absolutos sintéticos; 5) os deslocamentos à esquerda e à direita; e 6) os pronomes usados em orações relativas.

Para maior compreensão do cenário final identificado, apresentaremos brevemente os resultados encontrados.

Em primeiro lugar, observamos a variação na construção da posterioridade verbal a partir de duas variantes: o indicativo presente e o futuro indicativo. Nos e-mails, encontramos $100 \%$ de frequência do futuro 
indicativo. No plantão docente, houve, em 59\% dos casos, a expressão da posterioridade por meio do futuro indicativo, enquanto em $41 \%$ foi utilizado o indicativo presente. Nas entrevistas, a frequência foi a mesma para os dois tempos verbais. Nas mensagens de texto, há uma inversão da tendência geral, e $82 \%$ das formulações são construídas com o indicativo presente, ao passo que apenas $18 \%$ são realizadas com o futuro indicativo.

Quanto às conjunções, percebemos não apenas uma diferença no número total de conjunções usadas em cada corpus, mas também, e de modo especial, uma diferença no número de formas de conjunções empregadas nos diferentes gêneros textuais. Nesse sentido, nos e-mails foram identificadas 26 formas, enquanto nos plantões e nas entrevistas, treze, e nas mensagens de texto, quatorze.

Sobre o uso de unidades alteradas, observamos um aumento progressivo no emprego de diminutivos ao longo dos quatro corpora: nos e-mails não foi identificado termo alterado; nos plantões, apenas três ocorrências; enquanto nas entrevistas foram 33 e nas mensagens, 48.

No estudo das formulações com superlativos absolutos, verificamos que, nos e-mails, os superlativos atingiram apenas 25 ocorrências, nos plantões foram 21, já nas entrevistas foram 68 e nas mensagens de texto, 51.

No que diz respeito aos deslocamentos à esquerda e à direita, não encontramos ocorrências desses fenômenos nos e-mails, já nas entrevistas e nos plantões docentes, encontramos 34 ocorrências para cada conjunto de texto, e nas mensagens de texto trocadas por celular, 40 ocorrências.

Finalmente, no que se refere aos pronomes relativos, notamos a variação entre as variantes cui, quale e dove, empregadas com frequência distinta nos quatro corpora. De maneira geral, o pronome relativo cui esteve presente em todos os corpora, o pronome quale foi utilizado preponderantemente nos e-mails, enquanto dove foi visualizado, ainda que com baixa frequência, nos plantões docentes e nas entrevistas.

A partir desses resultados, construímos análises traçando algumas tendências de variação entre os fenômenos de acordo com o gênero textual,

TradTerm, São Paulo, v.37, n. 1, janeiro/2021, p. 119-147 Número Especial - Linguística de Corpus www.revistas.usp.br/tradterm 
seu grau de formalidade e o canal utilizado, e, então, formulamos um curso de língua italiana, alicerçado sobre técnicas de instrução explícita indutiva, que foi oferecido a onze alunos ao longo de sete encontros, com duração de três horas cada um.

No geral, os alunos participantes possuíam nível intermediário de competência comunicativa (atestado por meio de um teste conduzido antes do início do curso) e tinham média de idade de 30 anos, sendo a maioria deles estudantes da USP, ainda que não necessariamente alunos do curso de Letrasitaliano.

Como sugerido em Laviosa (1999), adotamos uma perspectiva mista de trabalho com corpus, organizada, num primeiro momento, a partir da análise dos textos orais e escritos que compunham os corpora reunidos na primeira etapa da pesquisa. Com base nesses textos, os alunos eram chamados a responder a questionários de interpretação, por meio dos quais se procurava estimular a reflexão acerca de questões relativas ao contexto de produção textual, como os objetivos da comunicação, o papel dos interlocutores, entre outros, características que, relacionadas à diamesia e à diafasia, poderiam sensibilizá-los quanto ao fenômeno da variação linguística. Parte de um desses questionários é reproduzida a seguir:

1. Passando ora all'analisi degli obiettivi di quest'e-mail, secondo voi qual è il suo scopo principale? Narrare eventi? Descrivere una scena? Prescrivere regole? Argomentare a favore di una tesi? Indicate i segmenti testuali che hanno motivato la vostra decisione.

2. Qual è il tipo di rapporto stabilito tra gli interlocutori? Quali scelte linguistiche permettono di identificarlo? Perché? ${ }^{7}$

Após discussão em duplas, os aprendizes expunham suas hipóteses ao restante da turma, e, na sequência, o professor thes fornecia feedback sobre

7 1) Passando agora à análise dos objetivos desse e-mail, para vocês, qual é o seu propósito principal? Narrar eventos? Descrever uma cena? Prescrever regras? Argumentar a favor de uma tese? Indiquem os segmentos textuais que motivaram a decisão de vocês. 2) Qual é o tipo de relação estabelecida entre os interlocutores? Quais escolhas linguísticas permitem identificálo? Por quê?

TradTerm, São Paulo, v.37, n. 1, janeiro/2021, p. 119-147

Número Especial - Linguística de Corpus www.revistas.usp.br/tradterm 
a adequação das respostas encontradas. Subsequentemente, solicitávamos que eles voltassem sua atenção a fenômenos linguísticos específicos (os mesmos que seriam posteriormente focalizados por meio da instrução explícita indutiva) e que refletissem sobre a possível conexão entre forma e função.

As questões inseridas a seguir constituem exemplos de como procedíamos. No caso específico reportado abaixo, trata-se de questionamentos que foram inseridos na terceira unidade didática, cujo objetivo era a apresentação do gênero e-mail, com foco especial na relação entre o contexto de produção, a seleção do registro e o emprego de conjunções mais associadas ao polo da formalidade.

1. Osserva nel testo il modo come l'autrice collega le proprie idee. Oltre a congiunzioni copulative, come "e", e dichiarative, come "che", lei usa congiunzioni che esprimono significati diversi, riesci a trovarle? Identifica queste congiunzioni sul testo e poi indica la funzione semantica che instaurano.

2. Secondo te, è possibile ipotizzare un rapporto fra la varietà di congiunzioni utilizzate in un testo e il grado di formalità richiesto dal contesto comunicativo? Perché?

Em seguida, ampliávamos a discussão e inseríamos quadros que sintetizavam as frequências diagnosticadas pela pesquisadora na análise conduzida nos corpora, requerendo dos alunos uma postura ainda mais ativa. Nesse momento, eles deviam se colocar na posição de "investigadores" da linguagem, justamente como sugerem Johns (1997) e Guidetti, Lenzi e Storchi (2012).

$\mathrm{Na}$ prática, pedíamos que eles observassem as frequências de ocorrência do fenômeno linguístico alvo da instrução nos quatro gêneros e que

8 1) Observa no texto o modo como a autora conecta as próprias ideias. Além de conjunções copulativas, como "e", e declarativas, como "che", ela usa conjunções que expressam significados diferentes, você consegue encontrá-las? Identifique essas conjunções no texto e depois indique a função semântica que instauram. 2) Para você, é possível levantar hipóteses sobre a relação entre as variedades de conjunções utilizadas em um texto e o grau de formalidade requerido pelo contexto comunicativo? Por quê?

TradTerm, São Paulo, v.37, n. 1, janeiro/2021, p. 119-147

Número Especial - Linguística de Corpus

www.revistas.usp.br/tradterm 
respondessem a algumas perguntas norteadoras, por meio das quais pretendíamos que pensassem na relação entre as diferenças na distribuição da variável estudada e a sua possível relação com elementos situacionais, como o papel do interlocutor, o objetivo da comunicação e o canal empregado.

Esse procedimento de apresentação foi respeitado em todos os encontros. Deve-se esclarecer que não houve nenhum tipo de explicação acerca da distribuição dos fenômenos linguísticos antes que os aprendizes refletissem sobre os quadros-síntese e as questões propostas a partir deles.

Para melhor entender o tipo de discussão que os dados baseados em corpus e os questionamentos lançados pela docente suscitaram, solicitamos aos aprendizes que gravassem suas interações com seus celulares e que as compartilhassem posteriormente conosco. Devido à limitação da dimensão desse artigo, na próxima seção, serão apresentados os resultados obtidos a partir do tratamento didático de quatro dos seis fenômenos linguísticos apresentados em sala de aula, quais sejam: 1) a variação na quantidade de formas de conjunções adversativas, causais, conclusivas e concessivas; 2) a variação no uso dos pronomes relativos; 3) a variação na presença de superlativos; e 4) a variação na presença de diminutivos ${ }^{9}$.

\section{Resultados: a LC e o estímulo à colaboração}

Como dissemos na seção anterior, após a inserção de questões de cunho interpretativo, a partir das quais procurávamos colocar em evidência os aspectos situacionais envolvidos na produção dos gêneros textuais, eram apresentados quadros-síntese com dados oriundos das análises prévias conduzidas pela professora/pesquisadora.

Trazemos a seguir o quadro introduzido na terceira unidade didática, no qual era mostrada a distribuição de cada conjunção nos quatro corpora, com a indicação entre parênteses do número de ocorrências atingido por cada

9 Durante as aulas, os fenômenos 3) e 4) foram tratados na mesma unidade didática e, portanto, serão aqui apresentados conjuntamente.

TradTerm, São Paulo, v.37, n. 1, janeiro/2021, p. 119-147 Número Especial - Linguística de Corpus www.revistas.usp.br/tradterm 
elemento. Na sequência, no Quadro 2, são elencadas as principais perguntas que motivaram as discussões dos aprendizes:

Quadro 2: Distribuição das conjunções nos quatro corpora

\begin{tabular}{|c|c|c|c|c|}
\hline Gênero & $\begin{array}{l}\text { Conjunções } \\
\text { adversativas }\end{array}$ & $\begin{array}{l}\text { Conjunções } \\
\text { causais }\end{array}$ & $\begin{array}{l}\text { Conjunções } \\
\text { concessivas }\end{array}$ & $\begin{array}{l}\text { Conjunções } \\
\text { conclusivas }\end{array}$ \\
\hline E-mail & $\begin{array}{c}\text { ma }(94) \\
\text { tuttavia }(12) \\
\text { però (11) } \\
\text { ciononostante (5) } \\
\text { bensi (2) } \\
\text { piuttosto (2) } \\
\text { eppure (1) }\end{array}$ & $\begin{array}{c}\text { poiché (32) } \\
\text { perché (28) } \\
\text { in quanto (24) } \\
\text { dal momento che } \\
\text { (11) } \\
\text { dato che (7) } \\
\text { siccome (2) } \\
\text { visto che (2) } \\
\text { giacché }(1)\end{array}$ & $\begin{array}{c}\text { nonostante } \\
\text { (19) } \\
\text { pur (8) } \\
\text { anche se (6) } \\
\text { sebbene (5) } \\
\text { seppur (2) } \\
\text { malgrado (1) }\end{array}$ & $\begin{array}{c}\text { quindi (25) } \\
\text { pertanto(13) } \\
\text { dunque (9) } \\
\text { cosi (6) } \\
\text { per cui (5) }\end{array}$ \\
\hline $\begin{array}{l}\text { Plantão } \\
\text { docente }\end{array}$ & $\begin{array}{c}\text { però (34) } \\
\text { ma (8) } \\
\text { invece (3) } \\
\text { mentre (1) } \\
\text { piuttosto che (1) }\end{array}$ & $\begin{array}{l}\text { perché (59) } \\
\text { visto che (2) } \\
\text { dato che (1) } \\
\text { siccome (1) }\end{array}$ & anche se (3) & $\begin{array}{l}\text { quindi (12) } \\
\text { perciò (1) } \\
\text { per cui (1) }\end{array}$ \\
\hline Entrevista & $\begin{array}{c}\text { però (96) } \\
\text { ma (19) } \\
\text { invece (14) } \\
\text { mentre (9) } \\
\text { anzi (4) } \\
\text { piuttosto che (3) }\end{array}$ & $\begin{array}{c}\text { perché (111) } \\
\text { siccome (6) } \\
\text { per il fatto che (1) }\end{array}$ & anche se (14) & $\begin{array}{l}\text { quindi (171) } \\
\text { perciò (3) } \\
\text { allora (2) }\end{array}$ \\
\hline $\begin{array}{l}\text { Mensagem } \\
\text { de texto }\end{array}$ & $\begin{array}{c}\text { ma (77) } \\
\text { però (27) } \\
\text { anzi (3) } \\
\text { invece (3) }\end{array}$ & $\begin{array}{l}\text { perché (53) } \\
\text { visto che (5) } \\
\text { siccome (1) }\end{array}$ & $\begin{array}{c}\text { anche se (9) } \\
\text { nonostante (1) } \\
\text { pur (1) }\end{array}$ & $\begin{array}{l}\text { quindi (34) } \\
\text { cosi (6) } \\
\text { perciò (2) } \\
\text { allora (2) }\end{array}$ \\
\hline
\end{tabular}

1. Secondo voi quale può essere la spiegazione perché il numero di congiunzioni usate nelle e-mail sia praticamente il doppio di quelle usate negli altri generi?

2. Quali sono le conseguenze di questa variazione nell'uso delle congiunzioni per un apprendente della lingua italiana? Può essere utile conoscerla? Perché? ${ }^{10}$

A partir da análise das gravações das discussões dos alunos, é possível depreender que as perguntas, de fato, ativaram procedimentos cognitivos de

10 1) Para vocês, qual pode ser a explicação para que o número de conjunções usadas nos emails seja praticamente o dobro das usadas em outros gêneros? 2) Quais são as consequências dessa variação no uso das conjunções para um aprendiz de língua italiana? Pode ser útil conhecê-la? Por quê?

TradTerm, São Paulo, v.37, n. 1, janeiro/2021, p. 119-147

Número Especial - Linguística de Corpus www.revistas.usp.br/tradterm 
análise que desencadearam, além do uso da língua-alvo, uma série de raciocínios de inferência baseados nos dados presentes nos quadros. 0 excerto a seguir, no qual as alunas discutem a primeira questão, parece apontar nessa direção:

\begin{tabular}{|c|c|}
\hline lena & $\begin{array}{l}\text { "poiché" non appare mai negli altri solo nella mail "perché" } \\
\text { appare in tutti ma quelli che sono più informale li mettono di } \\
\text { più tranne Whatsapp che c'è solo una volta ehhh" }\end{array}$ \\
\hline Coralina & "perché" è più usato nel ricevimento e nel Whatsapp \\
\hline lena & $\begin{array}{l}e \text { "visto che" è uguale penso che non viene usato da italiani } \\
\text { "visto che" sai che non avevo mai sentito "visto che" pensavo } \\
\text { che non era italiano pensavo che era un modo brasiliano }\end{array}$ \\
\hline & visto che \\
\hline & sai che non ho mai usato perché pensavo che non era italiano' \\
\hline
\end{tabular}

Aqui as aprendizes falam da frequência e dos tipos de conjunções ou locuções conjuntivas presentes nos gêneros. Elas constroem hipóteses interpretativas relevantes, como aquela identificada no primeiro turno, no qual associam a maior presença da conjunção poiché aos e-mails e a conjunção perché aos gêneros textuais mais informais.

Em seguida, elas passam a considerações quanto à locução visto che, em um primeiro momento, não identificada por Elena como uma conjunção usada por italianos. Logo depois, parece ocorrer o que Schmidt e Frota denominam noticing (1986), isto é, Elena parece se dar conta conscientemente da existência desse elemento, que, até então, segundo ela mesma, era visto como uma característica presente apenas na interlíngua de aprendizes brasileiros, sendo, portanto, evitado por ela.

11 Como a interlíngua dos aprendizes não será alvo de análise nesse trabalho, não serão indicados os eventuais erros presentes em suas produções. Os nomes dos aprendizes são fictícios, tendo sido escolhidos por eles durante o curso.

12 E: "poiché" não aparece nunca nos outros só no e-mail "perché" aparece em todos mas aqueles que são mais informais os colocam mais exceto Whatsapp que tem só uma vez ehhh /C: "perché" é mais usado no plantão e no Whatsapp / E: e "visto che" é igual, acho que não é usado por italianos "visto che" sabe que nunca tinha ouvido "visto che" achava que não era italiano achava que era um jeito brasileiro / C: visto che / E: sabe que nunca tinha usado porque pensava que não era italiano.

TradTerm, São Paulo, v.37, n. 1, janeiro/2021, p. 119-147

Número Especial - Linguística de Corpus www.revistas.usp.br/tradterm 
Durante as discussões relativas à segunda pergunta, as duplas passam a refletir sobre a utilidade de conhecerem essas distribuições. Uma das duplas, então, expõe sua opinião da seguinte maneira:
Julia
ah io credo che è importante sapere perché è diverso il modo
di parlare e di scrivere in italiano e a volte quando impariamo può succedere di che noi usiamo una congiunzione che non è adatta che non è la scelta per il parlato
Rodolpho non è la più comune in italiano per il madrelingua italiano
Julia non è la miglior scelta per il parlato
Rodolpho credo di si e anche perché se conosci quelle che è più usata se non si ricorda di un'altra si può usare questa ${ }^{13}$

Nesse fragmento, há, pelo menos, três aspectos que merecem destaque: em primeiro lugar, a observação da aluna Julia de que a modalidade falada diverge daquela escrita, indicando uma tomada de consciência acerca do conceito de variação linguística. Além disso, ela sustenta que aprender a distribuição das conjunções seria importante pelo fato de permitir uma maior adequação à modalidade da interação, comentário que permite entrever efeitos positivos das discussões em classe, uma vez que, em vez de operar com a dicotomia "certo/errado", ainda muito presente no âmbito do ensino de línguas, ela prefere trabalhar com a noção de “adequação/inadequação”, a nosso ver, muito mais congruente com uma visão de língua que contempla as variedades linguísticas. Finalmente, Rodolpho, em sua fala, considera que o conhecimento das conjunções mais frequentes pode compensar eventuais falhas na memória, o que nos permite depreender uma possível ligação entre esse tipo de conhecimento e o desenvolvimento de estratégias de compensação.

Passando nesse momento à análise das discussões decorrentes do tratamento didático da variação dos pronomes empregados nas proposições

$13 \mathrm{~J}$ : ah eu acredito que é importante saber porque é diferente o modo de falar e escrever em italiano e às vezes quando aprendemos pode acontecer que nós usamos uma conjunção que não é adequada que não é a escolha para a língua falada / R: não é a mais comum em italiano para o falante nativo / J: não é a melhor escolha para a língua falada / R: eu acredito que sim e também porque se você conhece as mais usadas se você não se lembra de uma outra você pode usar essa.

TradTerm, São Paulo, v.37, n. 1, janeiro/2021, p. 119-147 Número Especial - Linguística de Corpus www.revistas.usp.br/tradterm 
relativas, o quadro-síntese e o questionamento levados à sala de aula foram os seguintes:

Quadro 3: Distribuição dos pronomes relativos nos quatro corpora

\begin{tabular}{|c|c|c|c|c|}
\hline & E-mail & Plantão docente & Entrevista & $\begin{array}{c}\text { Mensagem de } \\
\text { texto }\end{array}$ \\
\hline Número total & 161 & 90 & 133 & 56 \\
\hline Tipos & 3 & 4 & 3 & 2 \\
\hline $\begin{array}{l}\text { Pronomes relativos } \\
\text { usados }\end{array}$ & $\begin{array}{l}\text { che: } 123 \\
\text { cui: } 22 \\
\text { quale: } 16\end{array}$ & $\begin{array}{l}\text { che: } 76 \\
\text { cui: } 11 \\
\text { quale: } 2 \\
\text { dove: } 1\end{array}$ & $\begin{array}{l}\text { che: } 113 \\
\text { cui: } 15 \\
\text { dove: } 5\end{array}$ & $\begin{array}{l}\text { che: } 52 \\
\text { cui: } 4\end{array}$ \\
\hline
\end{tabular}

1. Analizzando questo quadro, ti sembra che sia possibile indicare tendenze nell'uso dei diversi pronomi relativi a seconda del genere testuale ${ }^{14}$

Por meio da análise das transcrições das interações durante essa unidade de trabalho, foi possível constatar que os estudantes se mostraram bastante engajados na realização das atividades e interessados em buscar respostas congruentes com o que thes era pedido. Com efeito, em muitas duplas pudemos notar uma dinâmica particular, em que um dos alunos ocupa o papel de condutor da formulação das hipóteses, enquanto ao outro colega cabe concordar, refutar, aprofundar, colocar novas questões, pensar em novas alternativas de interpretação, promovendo uma interação em que ambos exercem papel ativo.

Em várias ocasiões ao longo das discussões, foi possível identificar uma alteração significativa no tom de voz e na velocidade de fala dos alunos, o que pode ser sinal de certa excitação ou exaltação, indicando, portanto, um aumento no grau de envolvimento dos alunos em relação às investigações que realizavam. Esse aspecto pode ser visualizado no trecho a seguir, extraído da produção de duas alunas do curso, no qual assinalamos em maiúsculo os segmentos aos quais elas dão maior ênfase:

Sylvia mer me la grande non so... è che qua TUTTI i pronomi
appariscono
Rafaella si

14 1) Analisando este quadro, parece ser possível indicar tendências no uso dos diferentes pronomes relativos de acordo com o gênero textual?

TradTerm, São Paulo, v.37, n. 1, janeiro/2021, p. 119-147

Número Especial - Linguística de Corpus

www.revistas.usp.br/tradterm 
Sylvia quello è il dato fondamentale qui, perché nel ricevimento TUTTI i pronomi appariscono quando negli altri no c'è una variazione se "dove" apparisce nelle interviste non apparisce nella mail $e$ nel Whatsapp non apparisce neanche "dove" neanche "quale"

Rafaella ma sai anche se noi in questa situazione del ricevimento abbiamo TUTTI i pronomi non si può indicare una TENDENZA grande perché "quale" si usa due volte, "dove" una volta vedi non è una TENDENZA

Sylvia ma ma se tu vedi qui ci sono il numero totale centosessantuno e nel ricevimento solo NOVANTA è quasi la metà, ma nella metà c'è una variazione MOLTO

Rafaella grande

Sylvia maggior

Rafaella maggiore maggior

Sylvia maggior che nel nel nella na esqueci a palavra até em português que na no DOBRO da do email

Rafaella dio non mi parli di numero cosi perché io ho fatto lettere come te não fala esse negócio de numero perché non mi va ma va bene ok

Sylvia quello che voglio dire qui c'è maior possibilità di apparire una diversità maggiore però non quello non succede e qui c'è una minor possibilità di apparire tutti i pronomi però APPARISCONO tutti i pronomi

Rafaella ho capito ho capito

Sylvia dunque PERCHÉ nel ricevimento succede cosi? Se la persona sta PARLANDO e la tendenza nel parlare è che si ripetano le strutture $i$ pronomi come abbiamo visto con le congiunzioni. Non so

Rafaella neanch'io non ho nessuna conclusione su questo ${ }^{15}$

Nesse momento da interação, são discutidas as ocorrências de pronomes relativos (cui, quale, che e dove) nos quatro gêneros textuais sob exame. 0 impasse das alunas reside no fato de a tabela revelar que há grande

15 S: Mas para mim a grande não sei... é que aqui todos os pronomes aparecem / R: sim / S: esse é o dado fundamental aqui porque no plantão todos os pronomes aparecem quando nos outros não tem uma variação se "dove" aparece nas entrevistas não aparece no e-mail e no Whatsapp não aparece nem mesmo "dove" nem mesmo "quale" / R: mas sabe mesmo se nós nessa situação do plantão temos todos os pronomes não se pode indicar uma tendência grande porque "quale" se usa duas vezes "dove" uma vez você vê não é uma tendência / S: mas mas se você vê aqui tem o número total cento e sessenta e um e no plantão só noventa é quase a metade mas na metade tem uma variação muito / R: grande / S: maior / R: maior, maior / S: maior que no no [na esqueci a palavra até em português que na no dobro da do email] / R: Deus não me fale de número assim eu fiz letras como você [não fala esse negócio de número] porque não gosto mas tudo bem ok / S: o que eu quero dizer aqui tem maior possibilidade de aparecer uma diversidade maior mas isso não ocorre e aqui tem uma menor possibilidade de aparecer todos os pronomes mas aparecem todos os pronomes / R: Entendi, entendi / S: Então por que no plantão acontece isso? Se a pessoa está falando e a tendência no falar é que se repitam as estruturas os pronomes como nós vimos com as conjunções não sei / S: Eu também não sei não tenho nenhuma conclusão sobre isso.

TradTerm, São Paulo, v.37, n. 1, janeiro/2021, p. 119-147 Número Especial - Linguística de Corpus www.revistas.usp.br/tradterm 
diversidade de formas pronominais nos plantões com professores, o que contraria, na visão de Sylvia, a tendência natural de, na fala, repetirmos sempre os mesmos pronomes.

No decorrer desse diálogo, como se visualiza, há o aumento no tom de voz das alunas que estão interagindo, principalmente a partir do quarto turno de fala, no qual a aluna Rafaella refuta a ideia expressa por Sylvia, procurando argumentar que não era possível falar de uma tendência em se utilizarem mais formas, uma vez que os números encontrados eram baixos.

A partir desse ponto, vemos um esforço de Sylvia em contraargumentar, descrevendo melhor o seu ponto de vista e, inclusive, lançando mão dos números presentes na tabela para fortalecer seu raciocínio. Sylvia deixa claro, então, seu anseio em reiterar sua perspectiva e em convencer Rafaella de que o que ela estava dizendo fazia sentido.

$\mathrm{Na}$ tentativa de reconstruir sua reflexão, Sylvia, em seu terceiro turno, parece constatar uma lacuna em seu repertório linguístico, o que lhe faz hesitar, dando a oportunidade para que Rafaella procure ajudá-la através do oferecimento da alternativa grande, não aceita por Sylvia, que opta então por testar maggior, uso que é ratificado por Rafaella.

Ocorre, aqui, o cruzamento de pelo menos três processos fundamentais para a aprendizagem da língua-alvo: em primeiro lugar, há o noticing the hole (SWAIN 1995), na medida em que Sylvia interrompe o fluxo conversacional por não conseguir encontrar uma maneira de expressar adequadamente sua ideia; em seguida, a colega, em uma nítida postura colaborativa (SWAIN 1995, 2000, 2005, 2006), oferece-lhe uma alternativa; posteriormente, há o teste de hipótese de Sylvia (SWAIN 2005) e, enfim, a confirmação colaborativa da pertinência do uso de maggior por Rafaella.

Na sequência, há uma nova ocorrência de noticing the hole, na qual Sylvia não consegue encontrar uma alternativa para o termo 'dobro', o que lhe faz passar ao português para se fazer entender. Ela então se justifica dizendo ter esquecido a palavra também na língua materna, o que, de certa maneira, acaba por abrir espaço para a utilização do português também por

TradTerm, São Paulo, v.37, n. 1, janeiro/2021, p. 119-147 Número Especial - Linguística de Corpus www.revistas.usp.br/tradterm 
parte de Rafaella, que fala em italiano, mas traduz em seguida seu enunciado para o português, como se tentasse convergir sua produção na direção de sua interlocutora.

Esse turno é finalizado com Rafaella dizendo que estava tudo bem, dando a entender que ela já havia entendido a perspectiva de Sylvia e que, sendo assim, podiam passar ao próximo tópico da atividade. Sylvia, no entanto, reafirmando o seu interesse no assunto, retoma a discussão e reformula seu argumento, sintetizando-o, dessa vez, sem rupturas no fluxo conversacional.

Rafaella, aparentemente tentando encerrar a discussão, diz ter entendido. Sylvia, então, em um tom que demonstra certa indignação em relação aos números presentes na tabela, coloca um questionamento final, que tem a função de resumir sua dúvida, ao mesmo tempo em que reitera sua argumentação. Rafaella diz não poder dar uma resposta à questão e, ao fazêlo, parece demonstrar ter aceitado a argumentação da colega.

Como se vê, as alunas interagem ativamente, criando uma atmosfera de uso autêntico da língua-alvo, na qual a discussão sobre elementos linguísticos (mas não estritamente estruturais) gera indagações, argumentações e conflitos muito próximos àqueles encontrados na vida diária. O foco na construção dos significados e na resolução dos problemas parece alavancar processos catalisadores da aprendizagem de línguas, como 0 noticing the hole e o diálogo colaborativo, além de favorecer 0 desenvolvimento de outras competências, como a discursiva, ligada à capacidade de argumentar em língua estrangeira.

$\mathrm{Na}$ quinta unidade didática, o objetivo central era considerar as características contextuais e linguísticas atinentes ao gênero "mensagens de texto" e a distribuição de superlativos e diminutivos ao longo do contínuo da formalidade na modalidade oral e escrita.

Para fomentar, sobretudo, discussões com vistas a atingir esse último objetivo, foi inserido o quadro-síntese abaixo, seguido de um questionamento 
que procurava direcionar o olhar dos aprendizes para a análise crítica dos dados:

Quadro 4: Distribuição dos superlativos e diminutivos nos quatro corpora

\begin{tabular}{|c|c|c|c|c|}
\hline & E-mail & $\begin{array}{l}\text { Plantão } \\
\text { docente }\end{array}$ & Entrevistas & Mensagens de texto \\
\hline $\begin{array}{l}\text { Superlati- } \\
\text { vo }\end{array}$ & \begin{tabular}{l}
\multicolumn{1}{c}{25 ocorrências } \\
$\quad$ Exemplos \\
benissimo (1) \\
fittissimo (1) \\
gentilissima (17) \\
grandissimo (1) \\
moltissimo (3) \\
puntualissimo (1) \\
vivissimo (1)
\end{tabular} & $\begin{array}{l}21 \text { ocorrências } \\
\text { Exemplos } \\
\text { benissimo (15) } \\
\text { tantissimo (5) } \\
\text { moltissimo (1) }\end{array}$ & \begin{tabular}{l}
68 ocorrências \\
\multicolumn{1}{c}{ Exemplos } \\
altissimo (3) \\
bellissimo (3) \\
benissimo (7) \\
buonissimo (1) \\
carissimo (1) \\
facilissimo (2) \\
famosissimo (1) \\
gradissimo (1)
\end{tabular} & $\begin{array}{l}51 \text { ocorrências } \\
\quad \text { Exemplos } \\
\text { agitatissimo (1) } \\
\text { al volissimo (1) } \\
\text { bellissimo (9) } \\
\text { benissimo (16) } \\
\text { bravissimo (2) } \\
\text { bruttissimo (1) } \\
\text { buonissimo (2) } \\
\text { cafonissimo (1) }\end{array}$ \\
\hline $\begin{array}{l}\text { Diminuti- } \\
\text { vo }\end{array}$ & 0 & $\begin{array}{l}3 \text { ocorrências } \\
\text { Exemplos } \\
\text { ragazzino (3) }\end{array}$ & $\begin{array}{l}\quad 33 \text { ocorrências } \\
\quad \text { Exemplos } \\
\text { amichetto(3) } \\
\text { annetto (4) } \\
\text { casina (2) } \\
\text { fratellino (3) } \\
\text { gruppetto (2) } \\
\text { macchinette (2) } \\
\text { macchinine (2) } \\
\text { oretta (2) }\end{array}$ & $\begin{array}{l}\quad 48 \text { ocorrências } \\
\quad \text { Exemplos } \\
\text { auletta (1) } \\
\text { bacetti }(2) \\
\text { bellina (1) } \\
\text { benino (2) } \\
\text { calduccio (1) } \\
\text { caruccio (1) } \\
\text { casetta (1) } \\
\text { chioschino (1) }\end{array}$ \\
\hline
\end{tabular}

1. Come interpretate i numeri presentati nella tabella? Come credete che si possa giustificare la differenza nel numero di occorrenze di superlativi $e$ diminutivi nei diversi generi ${ }^{16}$

No trecho abaixo, a dupla de alunas, procurando solucionar essa questão, diz:

$\begin{array}{ll}\text { Rafaella } & \begin{array}{l}\text { che non c'è una frequenza specifica per esempio agitatissimo } \\ \text { si usi molto no? si usa di forma molto mescolata e variata } \\ \text { uhhu } \\ \text { Julia }\end{array} \\ \text { Rafaella } & \begin{array}{l}\text { invece è nelle mail c'è un'occorrenza grandissima di } \\ \text { gentilissima io penso che come benissimo l'inizio della mail }\end{array} \\ \text { Julia } & \text { si } \\ \text { Rafaella } & \begin{array}{l}\text { gentilissima signora gentilissima tananan } \\ \text { Julia }\end{array} \\ & \begin{array}{l}\text { è questa cosa per rendere un po' più ehhh... eh come si dire } \\ \text { è per essere un po' più non rispettoso }\end{array}\end{array}$

16 Como vocês interpretam os números apresentados na tabela? Como vocês acreditam que se possa justificar a diferença no número de ocorrências de superlativos e diminutivos nos diferentes gêneros?

TradTerm, São Paulo, v.37, n. 1, janeiro/2021, p. 119-147

Número Especial - Linguística de Corpus

www.revistas.usp.br/tradterm 
Rafaella cortese

Julia giusto! cortese per rendere un po' più più cortese ${ }^{17}$

Como é possível depreender, uma das aprendizes toma a frente no levantamento de hipóteses. Nessa direção, ela enuncia sua interpretação sobre os dados: diz que não é possível detectar quais termos seriam mais propensos a serem usados no superlativo. Segundo afirma, não é possível estabelecer, por exemplo, que apenas o adjetivo agitato é empregado no superlativo, uma vez que o quadro revela que diversas outras formas poderiam ser candidatas ao processo de alteração. Além disso, ela supõe que a alta frequência de gentilíssima nos e-mails estaria relacionada à sua função vocativa, enquanto fórmula de abertura desse gênero textual.

Julia, que até então somente concordava com as ideias da colega, toma o turno e procura complementar as hipóteses de Rafaella. A seu ver, gentilissimo desempenha uma função específica nos e-mails, conferindo-lhe maior cortesia. No entanto, no momento de enunciar a parte final, ela hesita, percebendo não se recordar/não conhecer um termo capaz de expressar com precisão a sua ideia (noticing the hole), o que fica evidente quando diz "eh come si dire è?". Como não consegue achar um termo adequado, ela procura reconstruir seu pensamento e, no final, encontra a alternativa rispettoso (teste de hipótese), que, porém, não a satisfaz.

Rafaella então, em uma atitude colaborativa, oferece uma alternativa: cortese que, pelo tom exclamativo de Julia, constituía exatamente o termo que estava à procura.

Além das discussões estritamente linguísticas e sociolinguísticas provocadas pela inserção de questionamentos, fica claro que outros elementos são percebidos pelas aprendizes. Esse parece ser o caso da cortesia

17 R: que não tem uma frequência específica por exemplo "agitatissimo" se usa muito não? se usa de forma muito misturada e variada / J: uhhu / R: ao contrário nos e-mails tem uma ocorrência grandíssima de "gentilissima" eu acho que como "benissimo" o início do e-mail / $\mathrm{J}$ : sim / R: gentilíssima senhora gentilíssima tatananan / J: mas isso para deixar um pouco mais ehhh... eh como se dizer eh bem porque aqui são só superlativos e esse "gentilissimo" é para ser um pouco mais não respeitoso / R: cortês / J: exato! cortês para deixar um pouco mais cortês.

TradTerm, São Paulo, v.37, n. 1, janeiro/2021, p. 119-147

Número Especial - Linguística de Corpus

www.revistas.usp.br/tradterm 
atribuída ao apelativo gentilissima, que revela que as reflexões feitas de maneira autônoma durante as aulas abarcam tanto as competências mais diretamente ligadas ao âmbito linguístico quanto aquelas relacionadas aos usos e aos efeitos pragmáticos que os orientam.

Nesta seção, buscamos apresentar os resultados obtidos pela adoção de atividades didáticas construídas com base em corpora, conferindo particular relevo às inferências e aos processos cognitivos que parecem ser potencializados por elas. A seguir, concentramo-nos nas considerações finais.

\section{Considerações finais}

Esta pesquisa teve como objetivo central investigar as potencialidades de se construírem atividades didáticas baseadas em dados provenientes de corpora em contexto de ensino/aprendizagem de línguas estrangeiras.

Por meio da observação das transcrições de interações realizadas em duplas/trios, foi possível constatar o surgimento de produtivos debates entre os alunos, os quais possibilitaram o desencadeamento de processos conectados ao desenvolvimento da competência comunicativa. Em especial, observamos a ocorrência de noticing, noticing the hole, formulação e teste de hipóteses, diálogo colaborativo, além do aumento da oportunidade de expor argumentações complexas.

Em relação ao levantamento de hipóteses, verificamos que as interações ocasionaram a criação de hipóteses não apenas em resposta aos questionários que propúnhamos aos alunos, o que era previsto dado o desenho geral da pesquisa, mas também no decorrer das discussões, momentos nos quais a necessidade de expor as próprias ideias exigia que eles testassem estruturas e elementos lexicais.

Assim, acreditamos que os questionários e as discussões tenham favorecido duplamente o desenvolvimento de novos conhecimentos, pois se, por um lado, fomentaram o debate acerca da variação linguística, por outro,

TradTerm, São Paulo, v.37, n. 1, janeiro/2021, p. 119-147 Número Especial - Linguística de Corpus www.revistas.usp.br/tradterm 
forneceram ocasiões importantes para que os aprendizes testassem aquilo que sabiam e identificassem o que não sabiam.

Com os resultados da pesquisa, pudemos constatar a produtividade de se levarem as ferramentas da Linguística de Corpus à sala de aula, ampliando a reflexão linguística contextualizada, a compreensão da ligação entre forma e função, bem como impulsionando o desenvolvimento geral da competência comunicativa em língua estrangeira.

Para nós, essa tipologia de atividades pode ser adotada em diferentes contextos de ensino, tornando-se ainda mais crucial quando levada ao contexto de formação de novos professores, no qual o desenvolvimento de competências comunicativas deve se dar conjuntamente com 0 desenvolvimento da capacidade de análise metalinguística. 


\section{Referências}

Allora, A.; MARello, C. L'aggettivazione in scritti di apprendenti l'italiano come L2. In: BerninI, L.; SPREAFICO, A. V. (a cura di). Competenze lessicali $e$ discorsive nell'acquisizione di lingue seconde. Perugia: Guerra, 2008: 17-36.

BARBERA, M. La linguistica dei corpora in Italia all'alba del terzo millennio. In: Quanto più la relazione è bella: saggi di storia della lingua italiana 1999-2014. Tricase (LE): Youcanprint Self-Publishing, 2015: 117-138.

CALABRESE, R. Analisi dell'interlingua e sistemi di annotazione: implicazioni teoriche ed indagini empiriche. Testi e linguaggi, v. 4, pp. 151-158, 2010.Disponível em:

<http://elea.unisa.it:8080/jspui/bitstream/10556/685/1/Calabrese\%2 C\%20R.\%20Analisi\%20dell\%27interlingua\%20e\%20sistemi\%20di\%20annota zione.\%20Implicazioni\%20teoriche\%20ed\%20indagini\%20empiriche.pdf> $(20 / 03 / 2020)$

COLOMBO, O. L'apprendimento dell'alterazione in italiano $\mathrm{L} 2$ in produzioni scritte di francofoni. In: CoRINO, E.; MARELLO, C. (a cura di) VALICO. Studi di linguistica e didattica. Perugia: Guerra, 2009: 111-135.

CoRINO, E. Didattica delle lingue corpus-based. Educazione Linguistica. Language Education, v. 3, n. 2, 2014. pp. 231-257.

CoRINO, E. Varietà di apprendimento e subordinazione. Studi a cavallo tra VALICO e VINCA. In: CORINO, E.; MARELLO, C. (a cura di).VALICO: studi di linguistica e didattica. Perugia: Guerra, 2009: 71-95.

Dillenbourg, P. What do you mean by collaborative learning?. In: (ed.). Collaborative learning: cognitive and computational Approaches. Oxford: Elsevier, 1999: 1-19.

Dillenbourg, $\mathrm{P}$. et al. The evolution of research on collaborative learning. In: SPADA, E.; REIMAN, P. (ed.). Learning in Humans and machine: towards an interdisciplinary learning science. Oxford: Elsevier, 1996: 189-211.

Dunbar, K. Problem solving. In: Bechtel, M.; Graham, G. (eds.). A companion to cognitive science. London, England: Blackwell, 1998: 13-32.

FIGUEIREDO, F. J. Q. (org.) A aprendizagem colaborativa de línguas. Goiânia: Ed. da UFG, 2006.

FILIPIN, N.; MARDESIC, S. Analisi dell'interlingua nell'apprendente dell'italiano a livello universitario. Sraz LVII, 201-219, 2013. Disponível em: 
<https://www.academia.edu/10338988/Analisi_dell_interlingua_nell_ apprendimento_dell_italiano_a_livello_universitario>. (20/03/2020).

FrangIOTTI, G. A. A competência sociolinguística em italiano: da análise de dados de falantes nativos ao ensino implícito e explícito para brasileiros. 2019. $474 \mathrm{f}$. Tese (Doutorado - Língua, Literatura e Cultura Italianas) - Faculdade de Filosofia Letras e Ciências Humanas, Universidade de São Paulo, São Paulo.

FreItAS, L. V.; Freitas, C. V. Aprendizagem Cooperativa. Porto: Edições Asa, 2003.

GUIDETTI, M.; LenZI, G.; STORCHI, S. Potenzialità e limiti dell'uso dei corpora linguistici per la didattica dell'italiano LS. Supplemento alla rivista EL.LE. 2012. Disponível em: <https://www.itals.it/potenzialit\%C3\%A0e-limiti-dell\%E2\%80\%99uso-dei-corpora-linguistici-la-didatticadell\%E2\%80\%99italiano-ls>. (20/03/2020).

JoHNS, T. Contexts: the background, development and trialling of a concordance-based CALL program. In: WICHMANN, A.; FLIGELSTONE, S.; MCENERY, T.; KNOWLES, G. (eds.), Teaching and Language Corpora. Harlow: Addison Wesley Longman, 1997: 100-115.

LAVIOSA, S. Come studiare e insegnare l'italiano attraverso i corpora. Italica, v. 76, n. 4, p. 443-453, 1999. Disponível em:

<https://www.jstor.org/stable/480250?seq=1\#metadata_info_tab_con tents>. $(06 / 03 / 2020)$.

MARELLO, C. Corpora di apprendenti: come usarli nella didattica dell'italiano in Svizzera.In: DI PRETORO, R. Lingua e letteratura italiana 150 anni dopo l'Unità. Meidenbauer: Monaco. 2012: 299-315.

ONESTI, C.; SQUARTINI, M. L'acquisizione della perifrasi progressiva in italiano L2: questioni metodologiche. In: CORINO, E.; MARELLO, C. (a cura di). VALICO. Studi di linguistica e didattica. Perugia: Guerra, 2009. pp. 21-36.

SCHMIDT, R. Deconstructing consciousness in search of useful definitions for Applied Linguistics. Alfa Review, v. 11, 1994, pp. 11-26.

SCHMIDT, R. Awareness and Second Language Acquisition. Annual Review of Applied Linguistics, v. 13, 1993, pp. 206-226.

SCHMIDT, R. The role of consciousness in Second Language Learning. Applied Linguistics, v. 11, n. 2, 1990, pp. 129-158.

SCHMIDT, R.; Frota, S. Developing basic conversational ability in a second language: a case study of an adult learner of Portuguese. In: DAY, R.

TradTerm, São Paulo, v.37, n. 1, janeiro/2021, p. 119-147

Número Especial - Linguística de Corpus

www.revistas.usp.br/tradterm 
(ed.). Talking to learn: conversation in second language acquisition. Rowley, MA: Newbury House, 1986: 237-326.

SWAIN, M. Languaging, agency and collaboration in advanced second language learning. In: BYRNES, H. (ed.) Advanced language learning: the contributions of Halliday and Vygotsky. London, New York: Continuum, 2006: 96-108.

SWAIN, M. The output hypothesis: theory and research. In: HINDEL, E. (ed.), Handbook of research in second language teaching and learning. Yahweh, N.J: Lawrency Erlbaum Associates, 2005: 471-483.

SWAIN, M. The output hypothesis and beyond: mediating acquisition through collaborative dialogue. IN: LANTOLF, J. (ed.). Sociocultural theory and second language learning. Oxford: Oxford University Press, 2000: 97114.

SWAIN, M. Three functions of output in second language learning. In: CoOK, G.; SEIDLHOFER, B. (eds). Principle and practice in applied linguistics. Oxford: Oxford University Press, 1995: 125-144.

SWAIN, M. Communicative competence: some roles of comprehensible input and comprehensible output in its development. In: GASS, S.; MADDEN, C. Input in second language acquisition. Cambridge: Newbury House, 1985: 235-253.

ZAGREBELSKY, M. L'introduzione della corpus linguistics o linguistica dei corpora, nelle università italiane: una ricostruzione personale dagli anni '60 a oggi. Quaderni del CIRSIL, v. 4, 2005, pp. 203-213.

ZuLOAGA, M. Connettivi avversativi nei testi scritti da apprendenti ispanofoni di italiano per il corpus VALICO. In: CoRINo, E.; MARELLO, C. (a cura di).VALICO. Studi di linguistica e didattica. Perugia: Guerra, 2009: 179-193.

Recebido em: 29/03/2020

Aceito em: 07/10/2020

Publicado em janeiro de 2021

TradTerm, São Paulo, v.37, n. 1, janeiro/2021, p. 119-147

Número Especial - Linguística de Corpus www.revistas.usp.br/tradterm 